Peer-Reviewed Article

ISSN: 2162-3104 Print/ ISSN: 2166-3750 Online

Volume 7, Issue 3 (2017), pp. 449-466

(C) Journal of International Students

http://jistudents.org/

doi: 10.5281/zenodo.570295

\title{
Vietnamese Graduate International Student Repatriates: Reverse Adjustment
}

\author{
Anh T. Le \\ Barbara Y. LaCost \\ University of Nebraska-Lincoln, USA
}

\begin{abstract}
The purpose of this study is to explore the experiences of Vietnamese international students who have returned to Vietnam after graduation from a U.S. higher education institution. The findings suggest that participants found it harder to readjust to Vietnam than to adjust to the U.S. even though they had lived most of their lives in Vietnam. Time in the U.S. had changed them considerably, making it difficult for them to fit back into their old lives in Vietnam. Most of them did not expect to experience reserve culture shock, and most had made real efforts to fit back into the Vietnamese environment and culture.
\end{abstract}

Keywords: Vietnamese international students, Reverse culture shock, international student readjustment, international student repatriate

In the last decade, international students have become an integral part of the student population in the higher education sector (Bartram, 2007). International students contribute to the host country in several ways. Financially, international students and their dependents spend a substantial amount of money annually on tuitions, housing, food, and consumer goods. These expenditures make them a significant source of revenue for the local community (Lee, 2007). Skinner and Shenoy (2003) discussed multiple factors contributing to host countries' desire to attract international students. These factors may be categorized as economic, political/security, and academic. Economically, the benefits international students bring to the host countries are manifold. Besides paying for tuition and living expenses, international students also serve as research assistants and post-doctoral fellows who further research advancement in the host country, which improves the host country's competitive advantage in the global economy. 
Politically, a host country gains multiple benefits from hosting international students. International students provide the host community with the opportunity to be exposed to and learn from different cultures and political systems. Also, international students who return to their home countries usually bring with them good will about the host country. Educating international students is a great opportunity for the host country to influence future leaders who will guide the development of their home countries. Academically, international students contribute significantly to cultural and research diversity on campuses. International students, often among the top academic performers in their home countries, provide a healthy and stimulating competition to host countries' students. Given the great benefits that international students bring to host communities, the competition among countries to attract international students has been heightened. Countries that are making especially strong efforts to attract international students include the United States of America (henceforth, US), the United Kingdom, Australia, France, and Japan (Skinner \& Shenoy, 2003).

Research on international student mobility has been focused on the flow from home country to host country; less attention has been paid to what happens after graduation or after students return to their home countries, an issue often referred to as "reverse mobility" (Lee \& Kim, 2010). There are several reasons for a need for more research on international students' reverse mobility. First, the repatriates can serve as sources of information for other students who are interested in studying abroad. Second, host countries invest considerable amounts of human and financial resources (faculty, staff, advisor, assistantship, grants, etc.) into the education of international students, so they have an interest in acquiring knowledge about how these students utilize their training/education after graduation. Third, individual institutions and host countries' higher education systems are interested in learning about how relevant and useful the provided education has been for international students who return their home countries; knowledge gained can encourage them to provide targeted and pertinent improvements in their curricula and programs.

Within the limited pool of knowledge about the reverse mobility of international students, research has predominantly focused on students from traditional top-sending countries such as China, India, Korea, and Taiwan (Finn 2007; Jin, Lee, Yoon, Kim \& Oh 2006; Saxenian, 2005; Zweig, Fung, \& Han, 2008). According to the Institute of International Education (IIE) (2012a), Vietnam has consistently been among the top ten sending countries to the U.S. since 2009. In the 2011-2012 academic year, Vietnam was the eighth leading place of origin for students coming to the U.S., with 15,572 students (IIE, 2012b). However, very little research effort has been directed specifically toward Vietnamese international students, and even less 
research has addressed Vietnamese students who return to Vietnam upon graduation from a U.S. higher education institution.

The purpose of this study is to explore the experiences of Vietnamese international students who have returned to Vietnam after graduation from a U.S. higher education institution (henceforth, the repatriates). Areas explored include the transitional period, perceptions of the relevance of U.S. education to their current lives, reflections on their experiences in the U.S., and their future plans. Knowledge drawn from this study can serve as useful reference information for current and future recruitment efforts, support services, and courses geared toward Vietnamese international students.

\section{Definition of Terms}

International Student-A student from another country who is studying in the US on a non-immigrant student visa, classified as an F-1, M1, or J-1. This definition does not include permanent residents, resident aliens, "green card" holders, students on other sorts of visas, refugees, or immigrants.

Vietnamese international student repatriate - A Vietnamese student who returned to Vietnam upon graduation from a U.S. higher education institution.

\section{RELEVANT LITERATURE}

Few studies have investigated the repatriation experience (variously referred to as "return" or "reentry," as well) of international students (Sussman, 2002). Slightly more common in the literature have been studies on international students' intentions to stay in their host countries, but these few research studies have mostly been limited by country of origin, profession, or discipline. For example, Butcher (2002) considered East Asian students, Zweig and Changgui (1995) studied Chinese students, and Baker and Finn (2003) studied stay rates among international economics students in the U.S. What studies there have been about the repatriation experience have focused on (a) professional expatriates returning to their home country after working abroad or (b) U.S. study abroad students. For example, Şahin (1990) argued that repatriation distress among Turkish migrant workers correlated with the length of time abroad. Marital status and education level among missionaries have also been associated with the repatriation experience (Moore, Jones, \& Austin, 1987). U.S. study abroad students have reported that differences between home and host cultures affected their repatriation transition (Raschio, 1987). In addition, identity changes may be related to return home experiences (Isogai, Hayashi, \& Uno, 1999; Werkman, 1982). Several investigators reported positive reentry 
experiences such as (a) more appreciation of the host culture (Pritchard, 2010), (b) improved relationships with parents (Martin, 1986), (c) positive changes in values orientation (Uehara, 1986), and (d) more awareness and acceptance of cultural differences (Wilson, 1986).

Studies about the relationship between the abroad experience and the repatriation experience present conflicted findings. Cui and Awa (1992) found that sojourners with previous overseas experience adapted better to subsequent overseas assignments due to experience in coping with differences. Other researchers found an inverse relationship between overseas adaptation and repatriation such that the more successful the adaptation to a host country, the more distressing and difficult the return to the home country (Brein \& David, 1971; Brislin, 1981; Brislin \& Van Buren, 1974). Sussman (2000) has proposed a theory of the transition cycle using a social psychological framework, specifically focusing on selfconcept and cultural identity. The Cultural Identity Model (CIM) proposes several tenets: (a) cultural identity is a critical aspect of self-concept, (b) salience of cultural identity is a consequence of the commencement of a cultural transition, (c) cultural identity is dynamic and can shift as a consequence of the overseas transition and self-concept changes, and (d) shifts in cultural identity serve as a mediator between cultural adaptation and the repatriation experience.

In another study, Hazen and Alberts (2006) reported (a) the factors that international students consider in deciding whether to stay in the U.S. or to return home upon completion of their studies and (b) how these factors vary by nationality, gender, or academic major. They investigated international students' decision-making processes through focus groups and informal conversations with international students from a variety of disciplines and countries (Chinese, Dutch, Greek, Indian, Japanese, and Tanzanian). From the focus groups, they found that, generally, professional factors usually encouraged students to stay in the U.S., while societal and personal factors typically encouraged a return home. The majority of the students in the study stated that they had originally intended to return to their home countries after the completion of their degrees. The authors suggested that economic and professional factors typically act as strong incentives for international students to stay in the U.S., while personal and societal factors tend to draw students back to their home countries. More specifically, on the structural level, differences in job markets, economic opportunities, and political systems significantly influence the decisionmaking process. On an individual level, students' family connections, personal circumstances, and personalities account for much of the variation between students.

In one of the more highly cited studies of the reentry experience, Butcher (2002) conducted qualitative research with 50 graduates of New 
Zealand universities from Hong Kong, Malaysia, Singapore, and Thailand about the reentry process into their home countries. The article highlighted the difficulties faced by the graduates during the reentry process and offers suggestions for how to alleviate these difficulties. Butcher conceptualized the reentry as a grieving process. This grief, he posits, is best understood as a "disenfranchised grief" which is "a grief that can be defined as the grief that persons experience when they incur a loss that is not or cannot be openly acknowledged, publicly mourned, or socially supported" (p. 357). Because of the lack of expectations for and acceptance of reentry grief, returnees may experience many psychological challenges. Disenfranchised grief may exacerbate and intensify the normal reactions of grief, namely, anger, guild, sadness, depression, loneliness, homesickness, and numbness. The author found that the returnees specifically encountered challenges with (a) their return to family ties, (b) their change in their worldviews, and (c) their expectations of their reentry. Many returnees found it difficult to go back to living under their parents' roofs again. Their worldviews and expectations about familial responsibilities was different from their parents' worldview or expectations. Familial tensions were the norm for the returnees. Nevertheless, some returnees reported a better relationship with their parents because being away had helped them to appreciate their parents more.

Besides familial tensions, many returnees experienced disappointment with their employment situations. Butcher (2002) postulated that one of the most significant expectations of returnees might be immediate employment that would be relevant to their qualifications and that paid well. He declared this not to be the case. Many returnees quickly became dependent on parents because they had a hard time finding suitable employment even after applying for numerous jobs and waiting for several months. For an international graduate, entering a workforce for which they may not know the norms and conventions and for which they may not have been educated compounded the problem. Degrees in economics and management may have limited benefits to a graduate seeking employment in any of the countries addressed in this research (Butcher, 2002).

Mooradian (2004) later echoed Butcher's (2002) assertion of a myriad of difficulties facing international student returnees in their reentry process. Mooradian suggested that reverse culture shock differed from culture shock because there are many unexpected problems, in that people prepare for difficulties when they go abroad but often do not prepare for their reentry process. They expect home to have remained as they knew it when they return. However, many returnees reported feeling that people and relationships had changed while they were away. Mooradian speculated that returnees might feel a lack of support from their home social support networks, which could leave them feeling sad, lost, and lonely. However, 
Mooradian also acknowledged the positive advantages of the reentry process. Returnees could utilize many of the characteristics of the overseas culture to develop a new cultural identity that would work to their advantage at home. These characteristics can include interpersonal communication (accent or language competence), physical (fashion or appearance), and behavioral (posture or other nonverbal) attributes.

Mooradian (2004) asserted that reverse adjustment occurs in stages. The first stage, "leave-taking and departure", includes preparing to leave (saying goodbye, packing) and making logistical plans for going home. The second, "honeymoon stage," can last for about one month. As the returnees are newly back home, everyone is excited to see them, and they enjoy their time visiting people whom they missed while abroad. "Reverse culture shock," the third stage, begins when life starts returning to normal. The returnees realize that they have changed. They experience doubt and disappointment and are overwhelmed by the prospect of starting over. Alienation, rejection, loss of sleep, anxiety, and fears and phobias are among the common experiences of returnees. The fourth, and final, stage is "adjustment," when returnees begin to adapt to being at home, focus on the future, and try not to dwell on the past. According to Mooradian, it may take returnees from six months to a year to feel like they have readjusted to the home culture and to no longer experience a constant desire to go back to their host countries (p. 44).

The current literature on the reentry experience suggests that reentry/return/repatriation is a complex and stressful process involving several major aspects of the repatriates' lives including interpersonal relationships, career, and identity development. However, it is one of the most understudied and least discussed topics in the literature on student affairs work with international students. The aim of this study is to contribute to filling the gaps in the field's understanding of Vietnamese students' reentry experiences.

\section{RESEARCH METHOD}

\section{Population/Sample}

Study participants were seven Vietnamese international students who had graduated from a private university in the northeastern region of the U.S.; its functional pseudonym for the study was "Sunny University." There was no one comprehensive sample frame for this population. After obtaining Internal Review Board (IRB) approval, we reached out to potential participants using purposeful sampling and snowball sampling. The participants were purposefully selected based on two criteria: (a) graduated from the selected university and (b) had returned to Vietnam to live after graduation. We used snowball sampling after starting with a few 
key informants who had knowledge about or wide connections to people who might fit the study criteria.

\section{Data Collection Procedures}

The first researcher traveled to Vietnam and stayed for an extended period of time to conduct face-to-face interviews with the participants. Each interview lasted from 45 to 90 minutes and was audio recorded for accuracy. All of the participants chose to have conversations in Vietnamese. During each interview, the techniques of probing, seeking clarification, and paraphrasing were used to ensure the accuracy of the recorded information. During the interviews, the researcher took extensive handwritten field notes. The interview guide provided the opportunity to probe, to seek elaboration and clarification, and to paraphrase responses to ensure the accuracy of content and meaning in the transcription process. The inductive approach was used in this study.

\section{Data Analysis}

Because the interviews were conducted in Vietnamese, they were, of necessity, translated into English by the researcher. The translation was verified by another Vietnamese doctoral student to ensure its accuracy. The data collected for this study were analyzed using an inductive reasoning approach. Each transcript text was coded, and the codes were grouped into categories, which in turn were integrated into major themes. Descriptive coding was used to generate a set of codes that are words or phrases that "seem to stand out as significant or summative of what's being said" (Saldaña, 2011, p. 99). Codes from all transcripts were then clustered into categories based upon similarities. These categories were then further grouped into major themes. Themes are defined as "extended phrases or sentences that summarize the manifest (apparent) and latent (underlying) meanings of the data" (p. 108). A computer-assisted qualitative data analysis software called MAXQDA was used to cross-check the coding and theming process to ensure the validity of the codes and themes.

\section{FINDINGS}

In the interviews, both adjustment to the U.S. and readjustment to Vietnam were discussed at length. Interestingly, all of the participants found it harder to readjust to Vietnam than to adjust to the U.S. even though they had lived most of their lives in Vietnam. Time in the U.S. had changed them considerably, making it difficult for them to fit back into their old lives in Vietnam. For the purpose of presenting the findings, pseudonyms were used for the participants. There were four female participants (Daisy, Nancy, Lindsay, Tracy) and three male participants (Tony, Thomas, and David). 


\section{Table 1. The participants' demographic data}

\begin{tabular}{lclccl}
\hline Pseudonym & Age & $\begin{array}{l}\text { Marital } \\
\text { Status }\end{array}$ & $\begin{array}{l}\text { Years } \\
\text { spent in } \\
\text { the U.S. }\end{array}$ & $\begin{array}{l}\text { Years } \\
\text { back in } \\
\text { Vietnam }\end{array}$ & Current Occupation \\
\hline Daisy & 35 & Married & 2 & 2 & $\begin{array}{l}\text { Project Coordinator } \\
\text { English Teacher, }\end{array}$ \\
Lindsay & 27 & Married & 10 & 2 & $\begin{array}{l}\text { Interpreter } \\
\text { David }\end{array}$ \\
Tracy & 27 & Single & 2 & 1 & $\begin{array}{l}\text { Business Owner } \\
\text { Corporate Finance } \\
\text { Tony }\end{array}$ \\
Thomas & 27 & Single & 2 & 1 & Consultant \\
Nancy & 30 & Single & 11 & 4 & Consultant, Lecturer \\
\hline
\end{tabular}

All of the participants returned to Vietnam for relationship and career reasons. They had loved ones and support networks in Vietnam. Most of them also believed that they would have better career prospects in Vietnam because of its fast-growing economy and because of the availability of their social capital. However, for some, home did not feel like home anymore. They had changed significantly, which was something of a mixed blessing. The participants, themselves, usually perceived these changes as positive developments. Some of their loved ones appreciated the changes; others were skeptical of their value. From the participants' conversations about their readjustment processes, three common themes emerged: lost career opportunities, familial/romantic relationships, and cultural differences between Vietnam and the U.S., as they pertained to readjustment to life and work in Vietnam (i.e., reverse culture shock/readjustment to Vietnam).

\section{Loss of career opportunities}

All participants acknowledged that the time they had spent abroad was in many respects the best time of their lives. However, when they returned to Vietnam, they realized that they also had lost a few years of their careers. David, through his father's connections, was offered a job in a state-owned auditing company right after his bachelor's graduation. Thus, when David resigned from his position to go study abroad for two years, he forfeited a lucrative and highly sought after career opportunity. When he returned to Vietnam after two years, his colleagues had advanced in their careers. Additionally, he could not even return to his former position because the "economy was so difficult that I couldn't get the same opportunities like those anymore."

In Thomas' case, he felt that he had lost the competitive edge because "while my friends were working to accumulate experience and 
build their own networks, I was still a student and didn't keep pace with them." Similarly, Daisy had a tenured government job with many benefits, guaranteed job security, and high career advancement potential before her study abroad trip. When she came back, she was jobless because "they [the government] didn't know whether I would come back to contribute to the country." As a result, her position was terminated.

\section{Familial/Romantic Relationships}

Most participants expressed great concerns about their personal relationships. Depending on individual circumstances and life stages, their concerns varied in degree and in their specifics. However, participants all agreed that personal relationships played an important role in their lives and in their reasons for returning. Some of the participants were more fortunate than others in this area. For others, the decision to study abroad led to serious issues and outcomes.

Nancy, now in her mid-thirties, had gone through a divorce while trying to complete her MBA degree. Her daughter was just about three or four at the time. She actually had to interrupt her studies to come back to Vietnam to deal with her familial issues. When asked about what she had gained and lost as the result of studying abroad, Nancy admitted, "My biggest loss was my family." Currently, she lives with her daughter in her own house and is reportedly "very happy." However, given her extremely busy schedule, she shared, "My personal life has been limited at present." Another participant, Daisy, reported some similarities to Nancy's portrayal of personal life. Daisy also had a small daughter at the time she left for the U.S. Unfortunately, she will also soon become a single parent since she and her husband are currently going through the divorce process. Unlike Nancy and Daisy, Tracy was a single woman in her mid-twenties, but like them she also had lost a serious long-term relationship because she had chosen to study abroad. She also encountered difficult in her romantic relationships when she came back home. Parents, colleagues, and friends pressured her to settle down because she was "too old for getting married." Thus, she felt "trapped" and frustrated with her love life. She wished to have another opportunity because "if I study abroad, I might meet another international student whose world view is more similar to mine, more open and progressive. He might be more independent."

Beside romantic relationships, familial relation was a significant concerns for the participants. David experienced some familial tension with his parents. David mainly focused much of the interview on his relationship with his parents after he returned to Vietnam. He described how his parents reacted to his new characteristics: "Some are positive, some are negative. For instance, my parents were so pleased with my independence. However, that I came home late without informing made them upset." Like David, 
Tony placed great focus on his familial relationships. One of his most significant regrets from being abroad for so long was that he did not get to know his younger brother. He noted that on his return to Vietnam, his "younger brother was more mature. They [his family] were happy to have me back. So the positive outnumbered the negative." Furthermore, Tony had had a contentious relationship with his father before studying abroad. Upon his return to Vietnam, their relationship improved significantly as his father became less authoritarian as he got older and had converted to Buddhism.

The findings presented in this section depicted the participants' complex and diverse experiences with their familial/romantic relationships. In cases where the participants returned to live under their parents' roofs again, their familial relationships experienced some degree of change depending on the nature of their relationships before the trip and upon how much they had changed as persons. Both sides, the participants and their parents, for the most part were willing to modify their thinking and behaviors to accommodate each other to maintain familial harmony. Living abroad for at least two years appeared to make the participants realize how much they had missed their families and how much their parents care for them. As a result, they tended to take a more mature approach to familial conflicts than they would have done prior to their trips to the U.S. These themes mirror Butcher's (2002) results with 50 graduates of New Zealand universities from Hong Kong, Malaysia, Singapore, and Thailand. The author found that returnees specifically encountered challenges with their return to family ties, their change in their worldviews, and their expectations of their reentry. Many returnees often find it difficult to go back to living under their parents' roofs again. Their worldviews and expectations about their familial responsibilities might be substantially different from their parents' worldviews or expectations. Familial tensions are the norm for returnees, although some returnees reported having a better relationship with their parents because being away helped them to appreciate their parents more. However, the degree of familial tensions reflected in the current study is of much lesser degree. One possible explanation for this difference is the maturity level disparity between the two groups of participants, as Butcher's participants were mostly undergraduate students.

\section{Reverse Culture Shock}

Some of the participants experienced reverse cultural shock upon their return to Vietnam from the U.S. Five participants had lived their whole lives in Vietnam, except for the two years in the study abroad program. However, their whole worldviews had changed significantly because of their study abroad experience. They were more prone to get upset about things they used to consider normal. David described his 
frustrations with things he would have considered normal two years ago such as "those who run red lights or litter on the street or do not fasten seat belts, even my family." Similarly, Tracy had experienced more serious cultural shocks in many aspects of her life. Career wise, she was disappointed in how her American education became irrelevant as her job "was so different from what I had learned that I couldn't much apply my specialized knowledge on it." Her personal life also suffered because she "was under pressure and being pushed to settle down" and she "had to go on dates with guys that were completely incompatible with me." She was discouraged from pursuing her dreams:

I was accustomed to life in the U.S., so when I returned to Vietnam, I sometimes felt very exhausted because I had to readjust to life here. As you know, living in the U.S., I had the freedom to chase my dreams. Even if I wanted to spend four or five years to study higher, it was no problem. My dream was respected, so I didn't have doubts about making it come true. However, the Vietnamese don't approve that an almost thirty-year-old woman like me doesn't want to settle down but wants to study, instead. Each comment per person was enough for me to become dispirited. Chasing my dream is difficult; it's harder when nobody supports me and everyone tries to talk me out of it. So my dream is very limited here. Thus, if I could, I would go abroad again.

At work, she also felt left out because of cultural differences. She was used to the American working environment. Her current employment environment required her to engage in office politics and vicious (and sometime dirty) competition to get ahead. She could not fit in and did not want to compromise her moral integrity to gain career promotions.

Another participant, Thomas, also felt trapped in his life in Vietnam, although his problems were mostly just career related. For him, "the most disappointing issue was that I couldn't apply what I had studied in my real work" and "the way I think and talk about projects doesn't seem to fit the working environment in Vietnam." So, he felt "stuck."

Even Nancy, who was relatively successful in her transition and career, experienced some cultural shocks at first:

When I first came to work in VN, I felt that I was less energetic than my colleagues. Many overseas students usually met with the same situation. Many talk about how in the U.S. people often compliment your ability, while in Vietnam, you don't get that. I think it's cultural. For instance, American parents always praise their 
children, but the Vietnamese usually criticize their kids. It's part of the culture.

She also felt that she needed to show off more status symbols in Vietnam to gain acceptance from her networks. "I feel less pressured in the U.S. For example, here in VN, among my friends, I can't just ride a scooter, especially in Hanoi. In the U.S., nobody cares," she said in explaining why she had to own a car even though it is usually more convenient to get around on a scooter in Vietnam.

In general, all of the participants experienced reverse cultural shock to some degree when they returned to Vietnam. They had changed significantly while abroad. However, they had not anticipated that home would change, that friendships would disappear, and that people would judge them harshly because they had not followed the typical life trajectory for a Vietnamese. These experiences were also found in Mooradian's (2004) study. Mooradian suggests that reverse culture shock is different than culture shock because there are many unexpected problems. Many people prepare for difficulties when they go abroad, but often do not prepare for their reentry process. They expect home to have remained as they knew it when they return. However, as many returnees sadly discover, people change and relationships change. Returnees might feel a lack of support from their home social support networks, which leaves them feeling sad, lost, and lonely.

\section{Re-adjustment to Vietnam.}

Three participants, Tony, Lindsay, and Nancy, had relatively smooth transitions because they already found great career opportunities. The other four had to struggle to find employment. However, all of them adjusted their attitudes to adapt to their lives and career situations. David shifted his focus from what he had lost to what he could do now to be happy. Though he regretted wasting his American degree, he reframed the situation in a positive way: "the most important thing is how I can earn a living and how I can find a career and a lifestyle that are compatible with my interests, not what I have invested in. [...] the coffee shop business is my passion now."

Daisy shared that for her "it seemed that adapting to America was easier than readapting myself to Vietnam." When she first came back to Vietnam, she had to manage to support her family because everyone was dependent on her. However, she finally realized that she was somewhat successful at readjusting herself: "Only two weeks ago did I realize that I am not doing too bad." Similarly, Tracy reported feeling happy about being reunited with her family but also had to make significant adjustments. In some situations, she made adjustments to fit in with her colleagues. She 
made some compromises as "it was best that you lower yourself and ask to learn from others. [...] I sometimes had to speak in flattering terms to them."

Tony was much more fortunate than Tracy because he continued to work for a U.S.-based company after repatriation. He took up a second job to help with the re-integration into Vietnam. He attributed his successful transition from the U.S. to Vietnam partly to his positive attitude and flexibility: "I just try to make the best of my situation. In any circumstances, if I can't change them, I will change myself to adapt to reach better things." Similarly, Thomas also learned to accept the cultural differences and readjust himself to the environment and "gradually accepted that and adapted to my current life." When he had to drastically change his work philosophy to satisfy Vietnamese clients' needs, he felt conflicted. "Having to adjust to something which wasn't my nature certainly made me feel suffocated. However, I considered it a necessity of my job," he said. He considered it reasonable to critically examine which traits were appropriate for which cultures and make adjustment accordingly: "I will adapt to the foreign life when living abroad. And when I live with my family, I had to give up things that are not appropriate for this culture to get along with them."

Gender difference in readjustment. It would seem germane here to note that there were noticeable gender differences in the participants' perceptions of their readjustment experiences. The three male participants reported being happy or content with their love lives and careers. In contrast, of the four female participants, only one, Lindsay who was married to an American, was happy with her love life. Nancy's marriage was broken when she was still in the US. She was divorced by the time she returned to Vietnam. In her current high-powered position, she enjoyed a comfortable material and an active social life. However, she seemed to be constantly under stress at work and often worked long hours. Being a single mother, a career woman, and an extremely busy individual left her very little time for a personal life. She often felt "exhausted and lonely." Similarly, Daisy was going through a rough time as she was finalizing her divorce.

Conservative traditional gender norms proved to be powerful and detrimental to these female participants' pursue of happiness. Like Thomas, Tracy was a single individual in her late twenties. However, unlike Thomas, she was under extreme pressure both internally and externally to find a man to settle down with. However, she could not see herself being married to any of the men her family introduced her to. In her opinion, most of them were very patriarchal, "spoiled," and unambitious men who depended on their parents for financial support and obeyed their parents mindlessly. This sense of disappointment with potential dating partners was also voiced by 
several female participants in Pritchard's (2010) study about Asian graduate students' reentry trauma. She has changed, she said. She wanted to marry for love, not out of necessity. Thus, she was constantly in emotional turmoil and experiencing conflicts regarding her love life. In a relatively patriarchal society like Vietnam, women are often discouraged from pursuing higher levels of education or high-powered positions because doing so would make them less marriageable. Thus, the female participants in this study, except for Lindsay, who is married to an American, had to deal with this double standard on top of the common stressors of repatriation. The additional stresses and pressures for female repatriates has been documented in a number of studies on the reentry experience (Brabant, Palmer, \& Gramling 1990; Linehan \& Scullion, 2002).

\section{DISCUSSION}

Each participant's story is unique, of course. However, there were some characteristics common among most of the participants. Their exposure to the U.S. cultural traditions of valuing individual uniqueness and encouraging individual development made a strong impression on them. Some of them changed their worldviews and personalities drastically because of their experiences in the U.S. All considered, they felt that these personality changes were among the best things they gained from their study abroad experiences. However, these changes seemed to generate a mixed bag of reactions from the participants' loved ones and professional networks when they returned to Vietnam. Most of them found more emotional support when they came back to their families. For some, their familial relationships tended to improve upon their returns. Their parents appeared to be happy about their newly developed maturity and independence. However, such as in Nancy's case, her relationship with her father was worsened because he would not approve of her working in the private sector instead of in state-owned organizations.

Some of the participants were saddened by the fact that some of their friends had drifted apart when they came back from the U.S. The literature (Adler, 1981; Yoshida et al., 2002) suggests that this phenomenon is a common feature of the repatriation experience. In conversations about their careers, some participants were happier than others about their current employment conditions. Nancy, Lindsay, and Tony were the ones with the most positive perceptions of their jobs. Thomas and Daisy liked some aspects of their jobs but disliked the intense travel schedule and long hours. David could not find a suitable job and opened his own coffee shop. Tracy felt "dispirited" and "trapped" in a viciously competitive work environment where affiliation was valued more than expertise and hard work. This experience of career-related challenges was also reflected in the existing 
reentry literature (Riusala \& Suutari, 2000; Suutari \& Brewster, 2003; Westwood \& Leung, 1994).

Most of the participants were still struggling to readjust themselves to the Vietnamese working and living environments. All of them worked very hard and tried to keep a positive attitude. At the beginning of our conversations, they mainly focused on the positive aspects of their lives. Later on in the conversations, when the researcher and the participants had established rapport, they became more open to disclose deeper feelings and concerns about their personal and professional lives. For some of them, readjusting to Vietnam felt much more difficult than adjusting to the US during their study abroad time. This sense of misfit between their newly formed identity and their home country environment is reflected in the literature about cultural identity and cultural transitions (Sussman, 2000). For several, there was a sense of being "trapped" or "suffocated" because they had very little room in their lives for meaningful personal and professional development. Some had resolved to change themselves to fit into the environment, even though doing so might mean that they would have to give up a large part of the perceived positive development they had gained during their study abroad time. Others were seeking out opportunities to go abroad again to escape the miserable work environment. In other words, most of them had not adjusted well to the Vietnamese working environment even after more than one year home. These findings suggest that the readjustment process might take considerably longer than had been previously asserted in the readjustment stages model (Mooradian, 2004).

\section{CONCLUSION}

The principal intent of this study was to contribute some insights into the under-researched phenomenon of international student repatriation in Vietnam. The findings highlighted the critical concerns and issues for the participants. Each participant's story, as well as the group's commonality, was discussed to present the complexity of their lives as a whole and of their reentry experiences in particular. As a result of their time spent studying abroad, the participants have gained and lost important things in life, such as career opportunities, professional skills, and relationships. Their readjustment journeys were diverse but also had some common similarities. Most of them did not expect to experience reverse culture shock, and most had made real efforts to fit back into the Vietnamese environment and culture. For most, their readjustment journeys have been fraught with challenges and disappointments, especially the female participants. However, they all expressed a sense of hope and optimism for their futures because they felt that they had become stronger as a result of all of their 
experiences with cultural transitions. However, because of the life-changing, identify-altering experiences they had had overseas, their adjustment journeys will likely be long and complex processes.

\section{REFERENCES}

Adler, N. J. (1981). Re-entry: Managing cross-cultural transitions. Group \& Organization Management, 6(3), 341-356.

Baker J. G., \& Finn M. G. (2003). Stay rates of foreign national doctoral students in U.S. economics programs. Social Science Research Network. Retrieved from http://papers.ssrn.com/sol3/papers.cfm?abstract_id $=398640$

Bartram, B. (2007). The sociocultural needs of international students in higher education: A comparison of staff and student views. Journal of Studies in International Education, 11(2), 205-214.

Brabant, S., Palmer, C. E., \& Gramling, R. (1990). Returning home: An empirical investigation of cross-cultural reentry. International Journal of Intercultural Relations, 14(4), 387-404.

Brein, M., \& David, K. H. (1971). Intercultural communication and the adjustment of the sojourner. Psychological Bulletin, 76(3), 215-230.

Brislin, R. W. (1981). Cross-cultural encounters: Face-to-face interaction. New York: Pergamon Press.

Brislin, R. W., \& Van Buren, H. (1974). Can they go home again? International Educational and Cultural Exchange, 9(4), 19-24.

Butcher, A. (2002). A grief observed: Grief experiences of East Asian international students returning to their countries of origin. Journal of Studies in International Education, 6(4), 354-368.

Creswell, J.W. (2013). Qualitative inquiry and research design: Choosing among five traditions (3rd Ed). Thousand Oaks: Sage Publications.

Cui, G., \& Awa, N. E. (1992). Measuring intercultural effectiveness: An integrative approach. International Journal of Intercultural Relations, 16(3), 311-328.

Finn, M. G. (2007). Using NSF data on scientists and engineers to estimate stay rates of foreign doctorate recipients. Paper presented at the Workshop for Using Human Resource Data from Science Resources Statistics, National Science Foundation, VA.

Hazen, H. D., \& Alberts, H. C. (2006). Visitors or immigrants? International students in the United States. Population, Space and Place, 12(3), 201216.

Institute of International Education. (2012a). Open Doors data: International students: Leading places of origin [Data files]. Retrieved from http://www.iie.org/Research-and-Publications/Open-

Doors/Data/International-Students/Leading-Places-of-Origin

Institute of International Education. (2012b). Open Doors data: Fact sheets by country: 2012 [Data files]. Retrieved from http://www.iie.org/Researchand-Publications/Open-Doors/Data/Fact-Sheets-by-Country/2012

Isogai, T. Y., Hayashi, Y., \& Uno, M. (1999). Identity issues and reentry training. International Journal of Intercultural Relations, 23(3), 493-525.

Jin, M., Lee, S., Yoon, H., Kim, N., \& Oh, H. (2006). Careers of Korean PhDs with degrees of foreign countries and the HRD policy of the highly skilled in 
Korea. Seoul, Korea: Korea Research Institute for Vocational Education and Training.

Lee, J. J. (2007). Neo-racism toward international students. About Campus, 11(6), 28-30.

Lee, J.J., \& Kim, D. (2010). Brain gain or brain circulation? U.S. doctoral recipients returning to South Korea. Higher Education, 59(5), 627-643.

Linehan, M., \& Scullion, H. (2002). The repatriation of female international managers: An empirical study. International Journal of Manpower, 23(7), 649-658.

Martin, J. N. (1986). Communication in the intercultural reentry: Student sojourners' perceptions of change in reentry relationship. International Journal of Intercultural Relations, 10, $1-22$.

Mooradian, B. L. (2004). Going home when home does not feel like home: Reentry, expectancy violation theory, self-construal, and psychological and social support. Intercultural Communication Studies, 13, 37-50.

Moore, L., Jones, B. V., \& Austin, C. N. (1987). Predictors of reverse culture shock among North American Church of Christ missionaries. Journal of Psychology and Theology, 15(4), 336-341.

Pritchard, R. (2010). Reentry trauma: Asian reintegration after study in the West. Journal of Studies in International Education, 15(1), 93-111.

Raschio, R. A. (1987). College students' perceptions of reverse culture shock and reentry adjustments. Journal of College Student Personnel, 28(2), 156-162.

Riusala, K., \& Suutari, V. (2000). Expatriation and careers: Perspectives of expatriates and spouses. Career Development International, 5(2), 81-90.

Şahin, N. H. (1990). Re-entry and the academic and psychological problems of the second generation. Psychology \& Developing Societies, 2(2), 165-182. doi: $10.1177 / 097133369000200202$

Saldaña, J. (2011). Fundamentals of qualitative research. New York: Oxford University Press.

Saxenian, A. (2005). From brain drain to brain circulation: Transnational communities and regional upgrading in India and China. Studies in Comparative International Development, 40(2), 35-61.

Skinner, K. G., \& Shenoy, A. (2003). International students. In J. W. Guthrie (Ed.), Encyclopedia of Education (2nd Ed.). (Vol. 4, pp. 1310-1318). New York: Macmillan Reference U.S.A.

Sussman, N. M. (2000). The dynamic nature of cultural identity throughout cultural transitions: Why home is not so sweet. Personality and Social Psychology Review, 4(4), 355-373.

Sussman, N. M. (2002). Testing the cultural identity model of the cultural transition cycle: Sojourners return home. International Journal of Intercultural Relations, 26(4), 391-408. doi: 10.1016/S0147-1767(02)00013-5

Suutari, V., \& Brewster, C. (2003). Repatriation: empirical evidence from a longitudinal study of careers and expectations among Finnish expatriates. International Journal of Human Resource Management, 14(7), 1132-1151.

Uehara, A. (1986). The nature of American students reentry adjustment and perception of the sojourn experience. International Journal of Intercultural Relations, 10, 415-438. 
Werkman, S. L. (1982). Coming home: Adjustment problems of adolescents who have lived overseas. Adolescent Psychiatry, 7, 178-190.

Westwood, R. I., \& Leung, S. M. (1994). The female expatriate manager experience: Coping with gender and culture. International Studies of Management \& Organization, 64-85.

Wilson, A. H. (1986). Returned Peace Corp volunteers who teach social studies. Social Studies, 77(3), 100-106.

Yoshida, T., Matsumoto, D., Akiyama, T., Moriyoshi, N., Furuiye, A., Ishii, C., \& Franklin, B. (2002). The Japanese returnee experience: Factors that affect reentry. International Journal of Intercultural Relations, 26(4), 429-445.

Zweig, D., \& Changgui, C. (1995). China's brain drain to the United States: Views of overseas Chinese students and scholars in the 1990s. (China Research Monograph no. 47). Berkeley: Institute of East Asian Studies, University of California, Berkeley, Center for Chinese Studies.

Zweig, D., Fung, C. S., \& Han, D. (2008). Redefining the brain drain: China's "diaspora option". Science, Technology and Society, 13, 1-33.

ANH T. LE, PhD, is currently an academic advisor/success coach for international students at the University of Nebraska-Lincoln (UNL). Her research focuses on factors contributing to international students' success and identity development in undergraduate and graduate education in the United States. Email: ale10@unl.edu

BARBARA Y. LACOST, $\mathrm{PhD}$, is an associate professor in Educational Administration at the University of Nebraska-Lincoln. She has more than four decades of experience in the field of educational administration. She holds a doctorate from Louisiana State University. She has written several monographs and articles on educational administration, educational budgeting, and women in educational leadership. Email: blacost1@unl.edu

\section{Manuscript submitted: October 20, 2015 \\ Manuscript revised: March 2016 \\ Accepted for publication: October 27, 2016}

